\title{
ANALYZING SPINAL DEFORMITIES BY SPATIAL DATA EXTRACTED FROM COMPUTER GENERATED MOIRÉ IMAGES
}

Attila Drajkó, Ádám J. Kocsis, Péter Tamás, Ákos Antal

BUTE Department of Mechatronics, Optics, and Engineering Informatics drajko.attila@schmidt-bender.bu

\begin{abstract}
Moire measuring method is used widely throughout medical protocols, especially in the field of spinal diagnostics. In this article we will present an image processing method (written in National Instruments $^{\mathrm{TM}}$ LabVIEW $^{\mathrm{TM}}$ environment) to extract the height coordinates of a human back, by using the information provided by the moiré phenomenon formed on the surface. These data can be used to improve the accuracy of the two-dimensional deformation analysis (e.g. determination of Cobb Angle), or the relevance of three-dimensional aberrations (such as vertebral protrusions).
\end{abstract}

Keywords: moiré phenomenon, surface mapping, spinal diagnostics, image processing

\section{Introduction}

Moiré technique is a method widely used in various medical applications. In dental clinics, F.R. Wouters et al. used moiré phenomenon to examine gum swellings caused by dental implants. ${ }^{1}$ Richard Smith et al. applied it in the improvement of the dimensional accuracy of tooth implants. ${ }^{2}$ In plastic surgery, Sungyeon Ahn et al. developed a special grating to quantify the elasticity of human skin based on moiré strain analysis. ${ }^{3}$ Tetsuo Kawara defined the topography of human cornea by forming the grating with a special fluid. He was able to reach a $5 \mu \mathrm{m}$ of accuracy, and the method was useful in examining corneal deformities caused by cataract operations. $^{4}$

The most common field where moiré technique is used in medical practice is orthopedics. In the United States, more and more school nurses uses it for spinal deformity screenings. ${ }^{15}$ The main advantages are the relatively low cost, and the easy assembling of the measuring system (Figure 1), over and above the fast and simple interpretability. The moire fringes formed on the human back allows the examiner to find the characteristic points of spine clearly.

In this paper, we are going to present an image processing method to determine the threedimensional shape of the examined human back. At this point we note that this method can also be used on other surfaces, however further specifications are needed.

\section{Methods}

\subsubsection{Moiré technique}

The moiré phenomenon can be readily observed by superimposing two periodic or quasi-periodic structures. When the two structures have the same or slightly different line spacing and their lines 
are set approximately parallel, a new coarse pattern appears. This pattern is known as the moiré fringe pattern. The spacing and orientation of the moiré fringes depend on the spacing and orientation of the structures being overlapped whereas the visibility of fringes is related to the width of transparent or black lines with respect to the line spacing of the structures. ${ }^{5}$ Moiré topographical methods can be distinguished as: the basic grating-shadow, the grating-projection, the grating-TV and the synthetic, computer generated grating methods. ${ }^{6-7}$ Shadow moire is a contour mapping technique that involves positioning a grating close to an object and observing its shadow on the object through the grating. Thus, the basic grating-shadow method offers the best accuracy and the simplest arrangement because the projected grating and the master grating are identical, so they have the highest degree of binding. The disadvantage of the shadow moiré technique is that the master grating must have similar size as the measured object.

This optical method is one of the most modern ways for measuring the spatial shape of the human body. The advantages are the simultaneity and the non-contact way of measuring, so it does not influences the analyzed body. Furthermore, information is obtained from all of the points of the analyzed surface at the same time. Its measurement applicability is wide. ${ }^{8-9,16-18}$ This technique can also be used to determine deformation caused by pressure or by temperature change, in situations where measurement with mechanical processes cannot be carried out. It is also suitable to check dimensional accuracy of products made by mass production or in robotics. $^{10-12}$

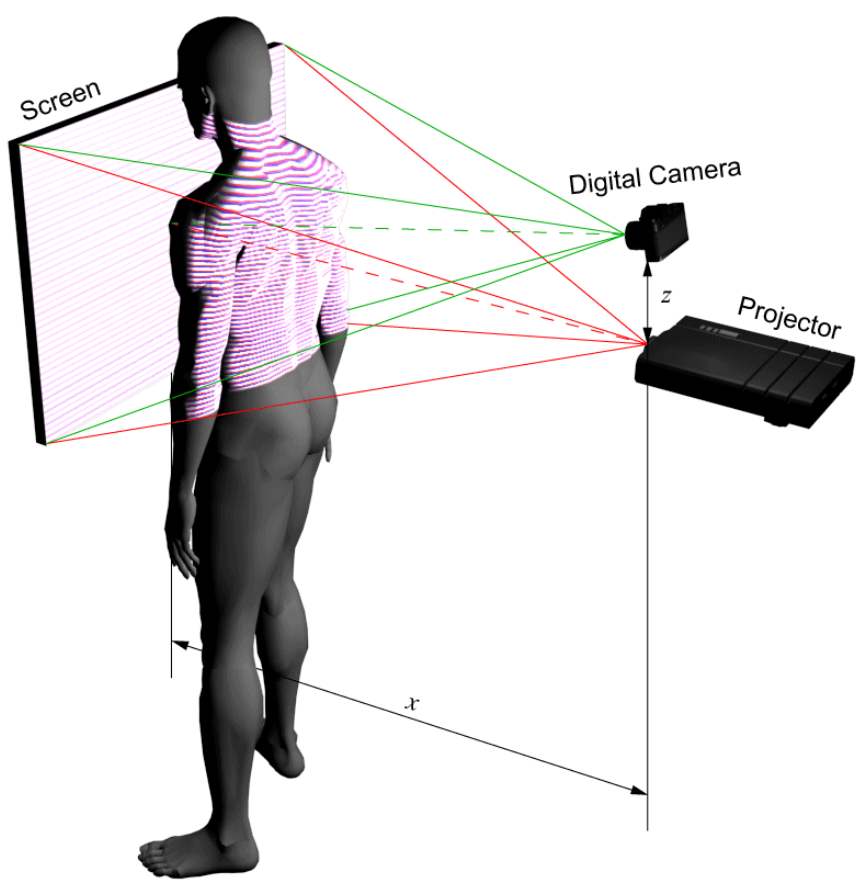

Figure 1. A classical moiré projection layout for human back examinations

In this research we used the color moiré technique to determine the directions of the surface. In 1980 A. Livnat, O. Kafri, and G. Erez defined and analyzed the so called "hill or valley" issue, caused by the ambiguity in the surface direction using the conventional black and white moiré gratings. ${ }^{13}$ In $1992 \mathrm{~K}$. Wenzel solved this problem by applying a bicolor projection grating. ${ }^{14}$ The 
color sequence formed by the moiré fringes defines the direction of the surface unequivocally. Figure 2 shows the advantage of this method, compared to the conventional moiré imaging.
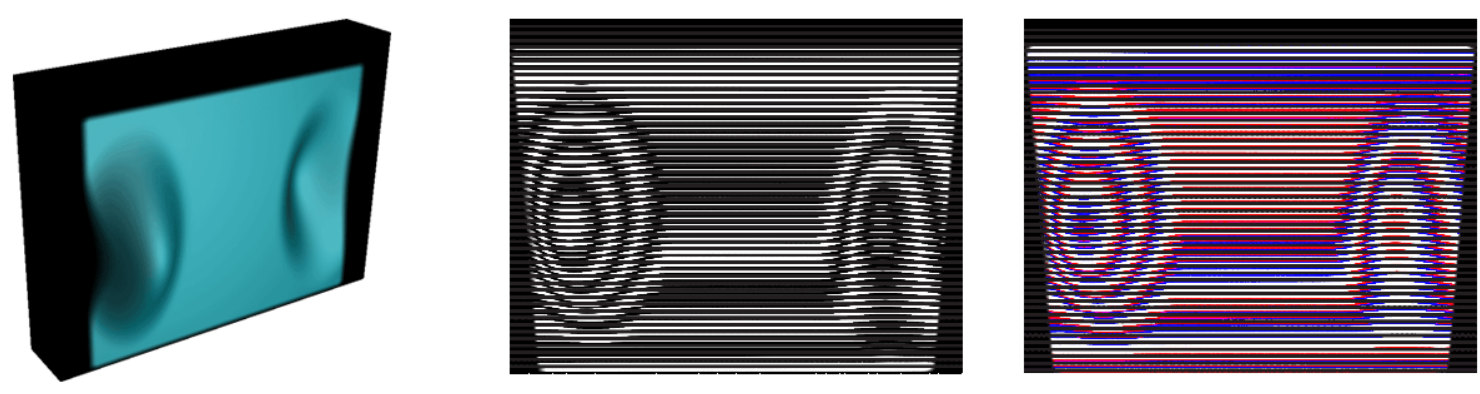

Figure 2. The "hill or valley" issue, and its solution

\subsubsection{The examined deformity: Idiopathic scoliosis}

The origin of idiopathic scoliosis is unknown, and its emergence cannot be prevented. However with frequent screening, it can be easily identified, and with proper treatment it can be stopped, and corrected. By definition idiopathic scoliosis is an abnormal spatial curvature of the spine, which occurs before bone maturation, causing structural deformities. The spine curves in frontal plane, twists in horizontal plane, and becomes concave in sagittal plane. It can develop in any age, which significantly influences its severity. The vertebrae have a reduced mobility, and in some cases the spine cannot be straightened.

\subsection{Simulation software}

The following software had been written in National Instruments ${ }^{\mathrm{TM}}$ LabVIEW ${ }^{\mathrm{TM}}$ environment, based on its Vision Development module. The purpose of the application is the capability to simulate projection environments from near ideal to near realistic. The input is an 8 bit depth grayscale PNG heightmap that codes the height information as the intensity of its pixels. Using these data we can easily generate the three-dimensional surface we want to analyze. During the simulation, we were using central projection to create the deformed projection grating on the surface. This and the reference grating can also be parameterized arbitrarily. Consequently, the moiré effect is fully customizable. Figure 3 illustrates the user interface of the simulation software.

The following equation is used for calculating the color of the surface using central projection:

$$
G_{p . y}=\frac{L_{y}-S_{p . y}}{L_{z}-S_{p . z}} \cdot\left(G_{p . z}-L_{z}\right)+L_{y}
$$

Where $S_{p . y}, S_{p . z}$ are the coordinates of the vertex of the analyzed surface, which the casted ray intersects, $G_{p . y}, G_{p . z}$ are the coordinates of the intersection of the casted ray and the reference grating and $L_{y}, L_{z}$ are the coordinates of the light source. 


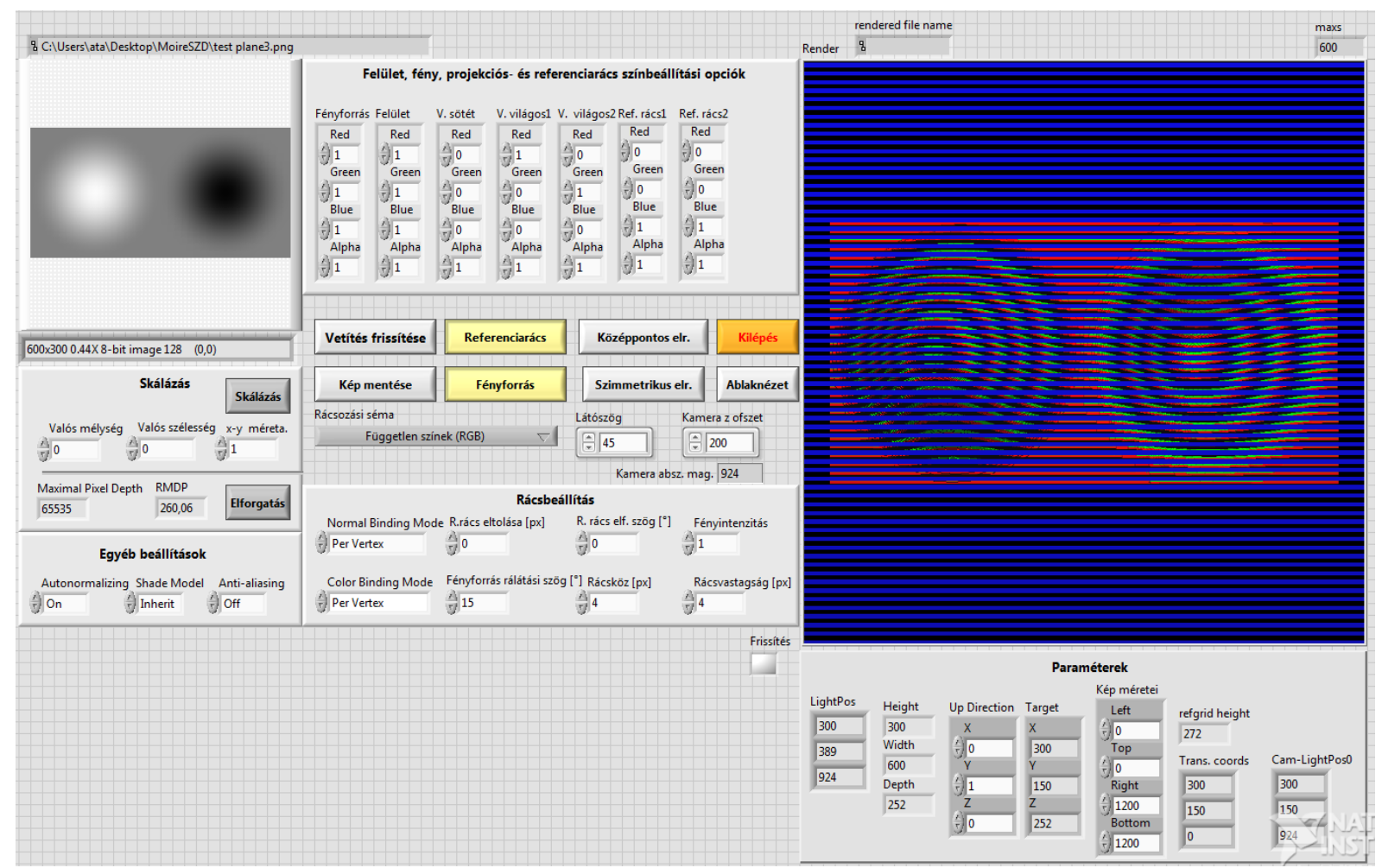

Figure 3. The user interface of the simulation software

Based on the experiments made with the software, we can conclude that the following parameters give the most characteristic and processable moiré effect (Figure 4):

- The optical axis of the digital camera is perpendicular to the screen, and intersects it at the central point.

- From top view, the axis of the camera and the projector are overlapped, and their distances from the screen are equal.

- On the side plane, the angle enclosed by these axes is $15-20^{\circ}$.

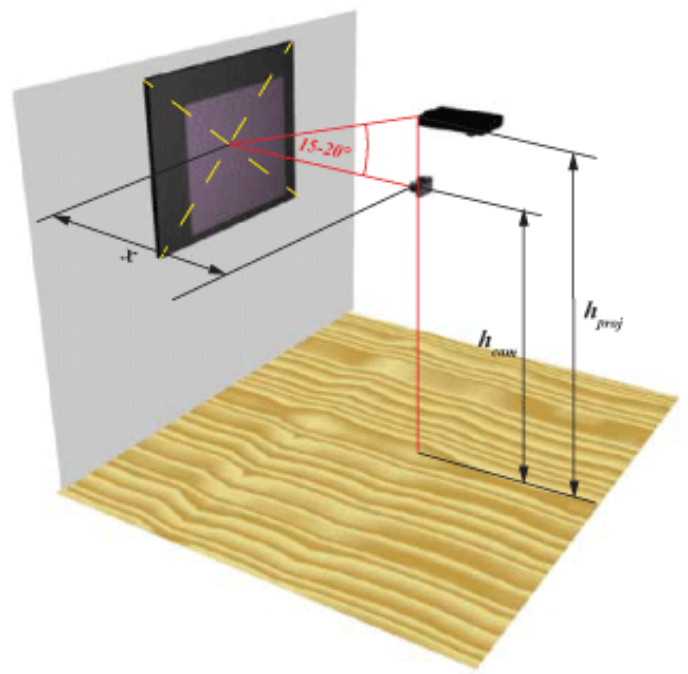

Figure 4. The optimal projection arrangement 
Further experiments revealed that the projected grating should consist of red $(R=255, G=0$, $\mathrm{B}=0)$ and green lines $(\mathrm{R}=0, \mathrm{G}=255, \mathrm{~B}=0)$, both with $\mathrm{k}$ width, and transparent lines with a width of $2 \mathrm{k}$ in this order. The reference grating should be blue $(R=0, G=0, B=255)$ with $2 k$ period. The colour differences help the image processor, presented below, to separate the reference grating, from the projected.

\section{Results}

\subsection{Image processing}

The cardinal issue of the image processing method is the precise separation and recognition of the moire fringes. The usage of color grating helps us clearly identify the direction of the surface part covered by the fringe. As the grating is a periodical structure, we can separate it from the other parts of the image using Fast Fourier Transformation, and a low-pass filter. The next step we use, is a threshold method with automatic clustering setting, built in LabVIEW, to exclude the pixels which are not associated with the fringe. After these, we apply the pattern recognition algorithms in Vision Development module, to get numerical information from the fringes, like area, perimeter, number of holes, coordinate of the first pixel, etc. Finally, a pixel sampling algorithm in two lines starts at the widest part of each contour, between the lines of the reference grating. By this method, color sequence of the fringe is defined, from which, the direction of the surface part can be determined directly. This algorithm analyses each contour, thus the surface topology is ready to be calculated. Figure 5 shows the user interface of the image processor.

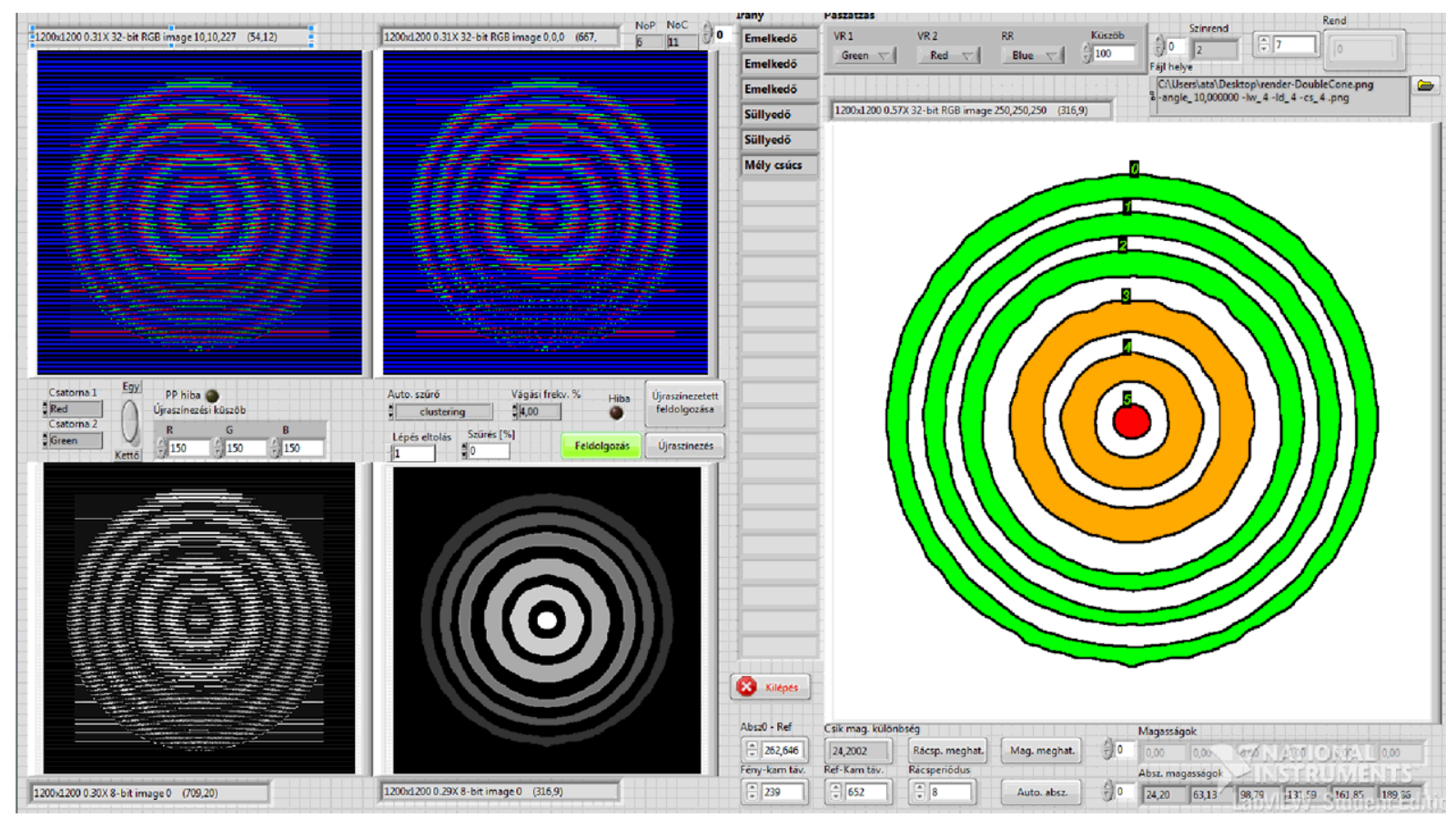

Figure 5. The user interface of the image processing software 

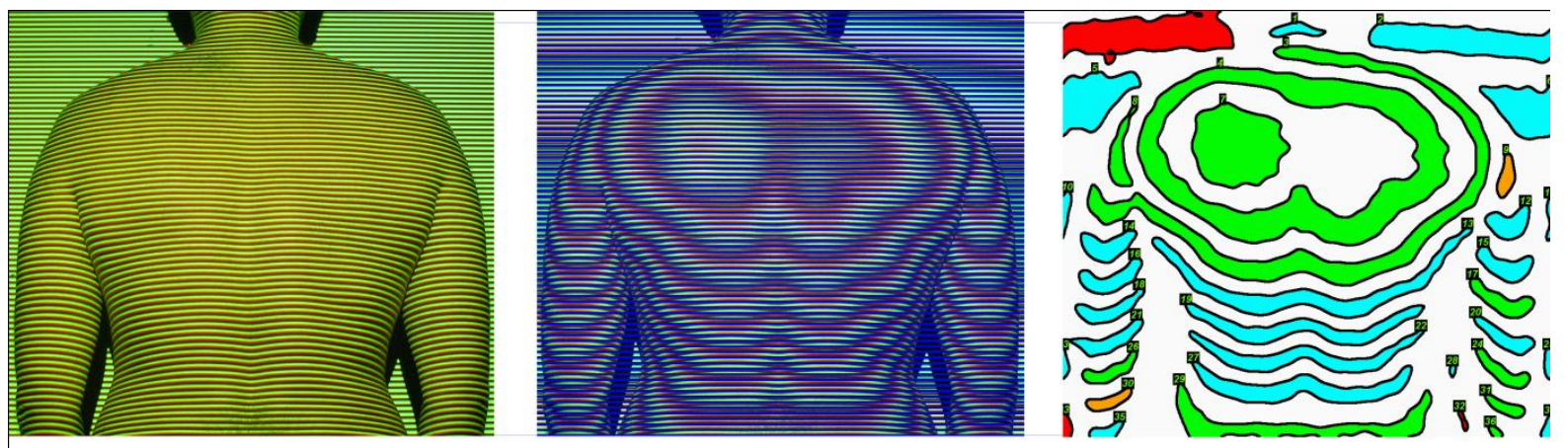

Figure 6. Phases of processing of human back

As Figure 6 shows, the presented algorithm separates the moiré fringes formed on the surface distinctly. Green areas represent rapidly raising surface parts, while cyan and orange parts have less or no climb respectively. This spatial data could be essential in evaluating vertebral deformities caused by scoliosis, not only on the plain of the surface, but in all direction.

\section{Conclusion}

The presented image processing method is useful in evaluating spinal deformities based on moiré images. However its accuracy significantly depends on the measurement parameters, basic information about the vertebral deformity can be gained in all directions, thus a thorough examination could be prescribed if necessary. This method should be useful in automatic deformity evaluation as well. Using the spatial information a spline fitting algorithm would be able to restore the original surface. Nevertheless, in this case the amount of unnecessary information, caused by redundant fringes formed on the environment, have to be minimized. As previously mentioned, the software can also be applied in any surface mapping applications, although further specifications would be needed.

\section{REFERENCES}

1. Wouters FR, Jon-And C, Abramson N, Olsson L, Frithiof P-Ö. Soder and I. Dirtoft, Measurement of Gingival Swelling from Dental Casts by Generation of a Moire Pattern with Laser Light. J DENT RES 1988;67:1118, DOI: 0.1177/00220345880670081101

2. Smith R, Zaitoun H, Coxon T, Karmo M, Kaur G, Townsend G, Harris EF, Brook A. Defining new dental phenotypes using 3-D image analysis to enhance discrimination and insights into biological processes. Archives of Oral Biology - 2009 December;54(Suppl 1):118-25, DOI: 10.1016/ j.archoralbio.2008.05.018)

3. Ahn S, Kim S, Lee H, Moon S, Chang, I. Correlation between a Cutometer ${ }^{\circledR}$ and quantitative evaluation using Moire topography in age-related skin elasticity. Skin Research and Technology, 2007;13:280-4. DOI: $10.1111 / j .1600-0846.2007 .00224 . x$

4. Kawara T. Corneal topography using moiré contour fringes, Appl. Opt. 1979;18,3675-8.

5. Patorski K, Kujawinska M. Handbook of the moiré fringe technique, Elsevier Science Publishers, New York; 1993. 
6. Windischbauer G. Survey on Applications of Moiré-Techniques in Medicine and Biology, in Optics in Biomedical Sciences, ed: G. von Bally, New York, Springer-Verlag: 1982. p. 244-9.

7. D’Acquisto L, Fratini A, Siddiolo M. A modified moiré technique for three-dimensional surface topography, Measurement Science and Technology, 2002;13(4):613-22.

8. Kamal SA. Determination of degree of correction of spinal deformity by moire topographs. In. Moire Fringe Topography and Spinal Deformity, Proceedings of the 2nd International Symposium, Gustav Fischer Verlag, Stuttgart, 1983. p. 117-26.

9. Neugebauer H. The different methods of measuring the curvature of scoliotic spine. In. Moire Fringe Topography and Spinal Deformity, Proceedings of the 2nd International Symposium, Gustav Fischer Verlag, Stuttgart, 1983. p. 17-26.

10. Dovica M. Komponenty a moduly mini- a mikromechanizmov. Monografi a. Edıcia vedeckej a odbornej literatury SjF TU v Kosiciach, Typo Press, Kosice, 2002. p. 150.

11. Dovica M, Gmiterko A, Henriczyova T. Basic Study of the Mobile Minimechanism for Moving Inside the Tubes with Small Diameter. 16. Internationales Kolloqium Feinwerktechnik 1997.October 1-3.

12. Katuch P, Dovica M, Henriczyova T. Walking mini-robots with compliant body. Proceedings of the sixth conference on mechanical engineering, 2008. May 29-30. Budapest, I7, ISBN 9634209478

13. Livnat A, Kafri O, Erez G. Hills and valleys analysis in optical mapping and its application to moiré contouring, Appl. Optics, 1980;19:3396-3400.

14. Wenzel K, Szines Moiré-Abra., Kép és Hangtechnika, 1992 November;38:33-64.

15. Adler NS, Csongradi J, Bleck EE. School Screening for Scoliosis-One Experience in California Using Clinical Examination and Moiré Photography, West J Med. 1984 November;141(5):631-3. PMCID: PMC1011169.

16. Dovica M, Kelemenová T, Henriczyová T. Súradnicová metrológia, Košice : TU - 2012. p. 483. ISBN 978-80-553-1120-3.

17. Dovica M, Kelemenová T, Henriczyová T, Kertész T. Tréningové podklady pre Súradnicovú metrológiu, Košice : TU - 2012. p. 307. ISBN 978-80-553-1121-0.

18. Kelemenová T, Henriczyová T. Metrotomografia - nástroj na meranie rozmerov tvarovo zložitých súčiastok, In: AT\&P Journal. Č. 9. 2009. p. 1-15. ISSN 1336-233X

The authors would like to thank National Development Agency (NDA) of Hungarian Government for its support since this study has been carried out commonly as part of project GERINCO2 TECH_08-A1/2-2008-0121. The work reported in the paper has been developed in the framework of the project „Talent care and cultivation in the scientific workshops of BME" project. This project is supported by the grant TÁMOP-4.2.2.B10/1--2010-0009. 